\title{
DCP THEATRE, DIRECT ACCESS AND A PALPABLE BUZZ...
}

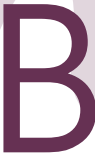

ritish Dental Association

(BDA) conferences

are always a hive of activity, excitement and

anticipation, with delegates looking for new ways to enhance their skills set, meet their peers and collect CPD, while companies are busy promoting and launching products.

The BDA's 2011 British Dental

Conference and Exhibition in

Manchester was no exception.

Over 4,500 delegates were offered a huge choice of topics, speakers and events over three days. From the inspirational opening keynote address by record breaking

Olympian athlete Tanni Grey-

Thomspon DBE, to seminars on oral cancer, periodontal medicine, the role of dental care professionals (DCPs) and how to manage CQC, there was a wealth of expertise and information on hand for every member of the dental health care team. Health Secretary Andrew Lansley MP was given a warm welcome and only a light grilling on the issue of reform and it was most encouraging to see so many people attending and actively participating in such a wide range of sessions.

For exhibitors, this annual event is a significant opportunity to catch up with clients and showcase the latest equipment and other products. Delegates were invited to 'try before they buy' and even offered the chance to take part in product workshops. With the wide range of samples on offer, no delegate managed to go home empty handed.

Despite concerns about contract reform, CQC and the economic climate, there was a real sense of enthusiasm about dentistry and a palpable buzz as delegates shared knowledge, experience and ideas.

In the dedicated DCP theatre, new for 2011, a range of speakers looked at issues central to the needs of the whole dental team. Here there was also a strong sense that dentistry is a rapidly evolving profession; technological advances and patient expectations are opening up areas of specialism while education and CPD are helping build dental teams

\section{Vivienne Wootten reports on the 2011 British Dental Conference and Exhibition, held at the Manchester Central Convention Complex.}

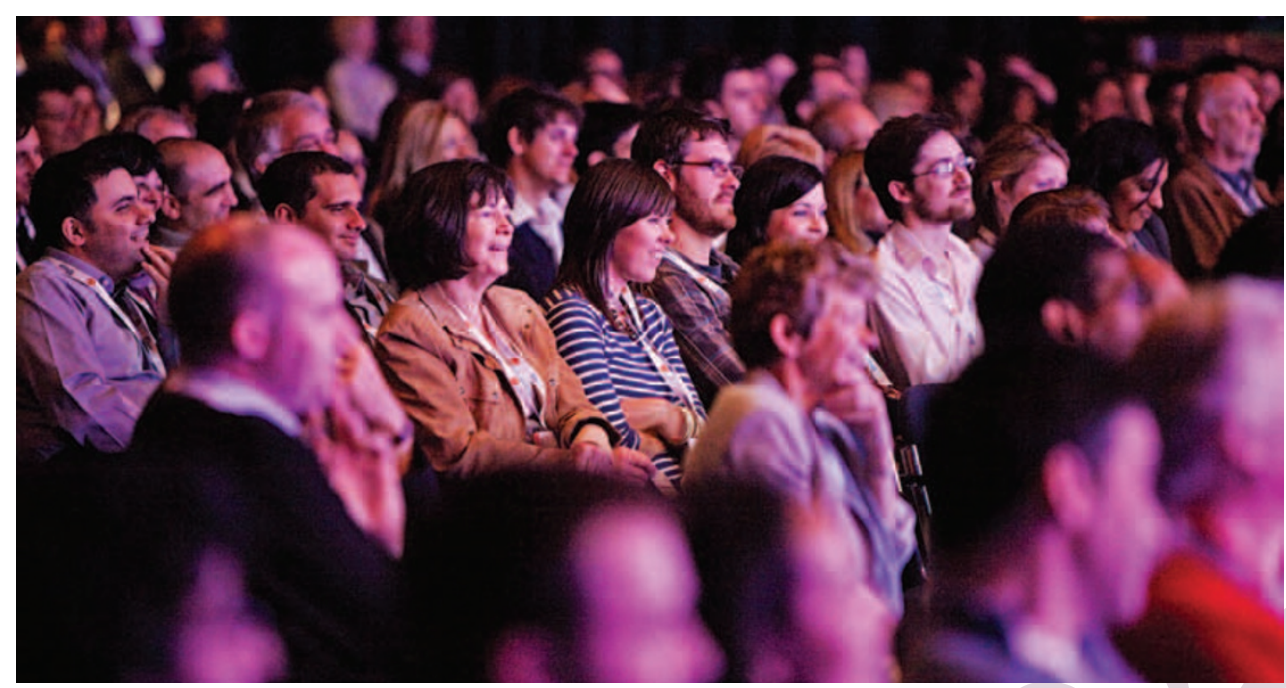

whose clearly defined roles and skill sets are world class.

This was an area touched on by Margaret Ross, Programme Director, Edinburgh Postgraduate Dental Institute in her seminar about the future impact of DCPs. Mrs Ross explained that there is a growing call for direct access to DCPs from patients, health and consumer groups who want an end to the need for referral. While there is recognition of the key role played by hygienists in non-surgical periodontal and preventative therapy, Mrs Ross pointed out that because hygienist education is now so much broader in remit and skills, they can undertake $70 \%$ of routine dentistry, preventative and perio care.

John Tiernan's highly entertaining but informative talk on complaints and how to minimise susceptibility to complaints was very well received as was Heather Dallas's useful talk on managing stress - a subject close to many delegates' hearts.

Although there were several lectures and discussion aimed at practice and professional management, this conference looked beyond dayto-day dentistry. One of the most thought provoking discussions was led by Professor Chris Holmgren, of St Radboud University, the Netherlands, who raised questions around whether short term volunteering is beneficial to people in developing countries where access to oral healthcare is very limited.
Professor Holmgren suggested a shift from the traditional high cost, low impact approach of short term volunteering towards capacity building for local people with the emphasis on prevention. This would reinforce the World Health Organisation's report on Oral Health Care, which recommends focusing on self care, simple curative fillings, prevention and emergency treatment which needs to be accessible, affordable and sustainable in order to make an impact in developing countries.

Indeed, prevention was a recurring theme of conference and many sessions underlined the significant role dental healthcare professionals have to play. One of the UK's leading experts in research on early cancer diagnosis, Dr Suzanne Scott, had a capacity audience to hear details of her work with particular reference to oral cancers. people being in denial or scared to seek help are not true it is ignorance of symptoms. The lack of knowledge about the existence of oral cancers, symptoms and treatments is a significant factor in early detection diagnosis and treatment. Dr Scott's lecture reinforced the key role dental health professionals can play in providing accurate and relevant information and advice, particularly by targeting patients in high risk groups such as smokers and drinkers over 40 . But the tone and approach of preventative intervention is absolutely key and the challenge is to raise awareness without raising anxiety.

The general consensus was that the 2011 event was a great success - stimulating, interesting, relevant and a unique opportunity to hear some of the profession's leading thinkers, practitioners and educators as well as meeting with a wide range of suppliers within the exhibition.

The date has already been set for next year when the event returns to Manchester on 26-28 April 2012. For more information on next year's event, visit www.bda. org/conference.
Her research suggested that common assumptions about 